\title{
"A Study on Performance Appraisal System at Wipro Infrastructure Engineering Pvt Ltd"
}

\author{
Dr.S.Jansirani, Mr. R.Hatrikrishnan, Mrs.D.Jaya kani, Ms.A.Saisathya, \\ Assistant Professor, Department of Commerce, Vels College, Pallavaram, Chennai -117
}

\begin{abstract}
In this study the operative function in the human resource department are analyzed with the contribution of employees and their opinion about the function performed by the employees and their opinion about the function performed by the HR Department in Wipro Infrastructure Engineering Pvt Ltd, Chennai.

The employees in the organization are directly interviewed and related data's where collected through the questionnaire. The data's are analyzed through the percentage analysis and chi-square method. From these inference were drawn, based on the inference it is found that most of the respondents fells that the performance appraisal system done by the organization is comfortable and satisfactory. From the study it is found that they are enriching their knowledge with appraisal system and necessary findings are made and suggestions were given.
\end{abstract}

Within a short period of time the employees are aware about the various policies are implemented by the company and also it gain goodwill in the minds of employees. Is suggested that the company should introduce new methods to provide good services promptly and efficiently at the time of employees' measures. Thus the study is mainly focus on performance of the employee among executives, and their opinion efficiently and effectively.

\section{Introduction}

Performance appraisal is an integral part of HRM and HRM deals with personnel is people. "People" is the important and valuable resource that every organization or institution has in the form of its employees. Dynamic people can build dynamic organization. Effective employees can contribute to the effectiveness of the organization. HRM has multiple goals, which include employee's competency development, employee motivation development and organization development. Employees require a variety of competencies, knowledge, attitude, skills in technical area; Managerial areas, behavioral and human relations areas and conceptual area to perform different tasks or functions required by their jobs.

HRM aim at constantly the competency requirements of different individual to perform the job assigned to them, effectively and provides opportunities for developing these competencies. As HRM deals with humans it is necessary to keep a check on their performance after regular interval of time given jobs, it is necessary to corrective actions term or there is need to appraisal their performance. The process of appraising for doing their work effectively is known as performance appraisal system.

It is very essential to understand and improve the employee's performance appraisal is the basis for HRD. It was viewed that performance appraisal was useful to decide upon employee promotion/transfer, salary determination and the like. Its roots in the early $20^{\text {th }}$ century can be traced to Taylor's pioneering Time and motion studies. As a distinct and formal management procedure used in the evaluation of work performance, appraisal really dates from the time of the Second World War - not more than 60years ago. Yet in a broader sense, the practice of appraisal is a very ancient art. In the scale of things historical, it might well lay claim to being the world's second oldest profession. Performance appraisal measures the qualitative and quantitative aspects of job performance.

"There is a basic human tendency to make judgments about those one is working with, as well as about oneself." Appraisal, it seems, is both inevitable and universal. In the absence of a carefully structured system of appraisal, people will tend to judge the work performance of others, including subordinates, naturally, informally and arbitrarily. The human inclination to judge can create serious motivational, ethical and legal problems in the workplace. Without a structured appraisal system, there is little chance of ensuring that the judgments made will be lawful, fair, defensible and accurate. Performance appraisal systems began as simple methods of income justification. That is, appraisal was used to decide whether or not the salary or wage of an individual employee was justified.

The process was firmly linked to material outcomes. If an employee's performance was found to be less than ideal, a cut in pay would follow. On the other hand, if their performance was better than the supervisor expected, a pay rise was in order. Little consideration, if any, was given to the developmental possibilities of appraisal. If was felt that a cut in pay, or a rise, should provide the only required impetus for an employee to 
either improve or continue to perform well .Sometimes this basic system succeeded in getting the results that were intended; but more often than not, it fail.

For example, early motivational researchers were aware that different people with roughly equal work abilities could be paid the same amount of money and yet have quite different levels of motivation and performance .These observations been confirmed in empirical studies. Pay rates were important, yes; but they were not the only element that had an impact on employee performance. It was found that other issues, such as morale and self-esteem, could also have a major influence.

As a result, the traditional emphasis on reward outcomes was progressively rejected. In the 1950s in the United States, the potential usefulness of appraisal as tool for motivation and development was gradually recognized. The general model of performance appraisal, as it is known today, began from that time.

\section{STATEMENT OF THE PROBLEM:}

Much of literature dealing with Human Resource Management and its issues recognize the importance of performance appraisal system which occurs in the organization. All organization faces the problem of directing the energies of their staff to the task of achieving business goals and objectives. In doing so, organization need to devise means to influence and channel the behaviors' of their employees so as to optimize their contributions. Performance appraisals constitute one of the major management tools employed in this process.

The continuous evolution of organization towards the changes creates a great impact in the life of the business still, the business leaders are relying on the capacity of the people and their performance towards their job and roles in the organization. Whether a profitable or non - profitable organization, the people has been essential resources in the organization. Various strategies had been effectively used for the employee according to their different needs and areas that needs to sustain.

However, there is a little attention given in enhancing the employee performance appraisal system.

The present study was under taken to clarify certain questions related to the care phase of performance appraisal through regular assessment of progress toward goals focuses the attention and efforts of an employee or a team.

\section{SCOPE OF THE STUDY:}

$>$ This study provide appraisal feedback to employees and thereby serve as vehicles for personal and career development and allow the management to take effective decision against drawbacks for the well being of the employee's development.

> To improve employee work performance by helping them realize and use their full potential in carrying out their firms' mission.

$>$ The main aim of the study is to find out the effectiveness of performance appraisal \& development programme conducted at "Wipro Infrastructure Engineering".

$>$ This study helps to know the level of importance of appraisal system.

$>$ The payroll and compensation decision, training and development needs, promotion, demotions transfer including job analysis and providing superior support, assistance and counseling.

$>$ It considers both the job performance as well as the personal qualities of an employee.

\section{NEED OF THE STUDY:}

$>$ This study helps building progress towards organizational goals.

$>$ To help the superior to have a proper understanding about their subordinates.

$>$ To ensure organizational effectiveness through correcting the employee for standard and improved performance and suggesting the changes in employee behavior.

$>$ It provides information about the performance ranks.

$>$ To provide information this helps to counsel the subordinates.

$>$ To facilitate fair and equitable compensation based on performance.

\section{PRIMARY OBJECTIVE:}

\section{Objectives Of The Study:}

To identify the actual performance of the employees and performance standards used in performance appraisal program (opinion, satisfaction, benefit, outcome, etc.).

\section{SECONDARY OBJECTIVES:}

$>$ To create and maintain a satisfactory level of performance.

$>$ To identify the awareness level of performance appraisal technique among the employees.

$>$ To maintain records in order to determine compensation packages wage structure, salaries raises etc. 
$>$ To identify the strength and weakness of employee to place right men on right job.

$>$ To maintain and assess the potential present in a person for further growth and development.

$>$ To provide feedback to employees regarding their performance and related status.

$>$ To review and retain the promotional and other training programmers.

\section{Limitation Of The Study:}

* This study is only limited to Wipro infrastructure engineering pvt ltd in SIPCOT branch alone.

* Some of the respondents were afraid to give true information in some cases.

* There may be bias on the part of employees while answering to the questions.

* The sample size of the study is limited to 150 not the entire employees of the organization.

\section{MEANING OF THE STUDY:}

Performance appraisal is an exercise they typically do once a year to identify and discuss job-relevant strengths and weaknesses of individuals or work teams. Performance appraisal is a method of evaluating the behavior of employees in the work spot, normally including both the quantitative and qualitative aspects of job performance. Performance here refers to the degree of accomplishment of the tasks that make up an individual's job. It indicates how well an individual is fulfilling the job demands. Often, the term is confused with effort, but performance is always measured in terms of results and not efforts. Some of the important features of performance appraisal may be captured thus:

- Performance appraisal is the systematic description of an employee's job relevant strength and weakness.

- The basic purpose is to find out how well the employee is performing the job and establish a plan of improvement.

- Appraisals are arranged periodically according to a definite plan.

- Performance appraisal is not job evaluation. It refers to how well someone is doing the assigned job.

- Performance appraisal is a continuous process in every large scale organization.

Robert Owen, a Scottish mill owner in the early $19^{\text {th }}$ century, first evolved the system of merit rating.

Merit rating or performance appraisal is concerned with measuring and evaluating employee performance after he is placed on a job. In those days the task of measuring the employee's efficiency was left to the judgment and opinion of the managers. But in modern times, a scientific approach is needed to find out the qualities and merit of the performance of the individual employee. The merit rating technique provides for a systematic and scientific assessment of the ability of the employee.

Performance appraisal is the systematic evaluation of the performance of employees and to understand the abilities of a person for further growth and development. Performance appraisal is generally done in systematic ways which are as follows:

1) The supervisor measures the pay of employees and compares it with target and plans.

2) The supervisor analysis the factors behind work performance of employees.

3) The employees are in position to guide the employees for a better performance.

Performance appraisal also means an appraisal of the growth potential of an employee, with a view to providing information to the organization leading to positive action and enabling feedback to the individual aimed at his performance improvement, personal growth and job satisfaction. In short we can say that performance appraisal to result in an assessment of:

a) Growth potential of employees.

b) Corresponding training needs for the employee.

c) Capabilities for their placement in higher posts.

d) Conduct of disciplines of the employees.

Performance appraisal systems have always played a very important role in human resource management. The performance appraisal is critical mechanisms for organizational control, through which the employees can view, see their past performance and take action for improvement.

\section{DEFINITION:}

"Performance appraisal is the systematic evaluation of the individual with regard to his or her performance on the job and their potential for development"_ BEACH

According to DALE YODGER,” Performance appraisal to all formal procedures aimed working organization to evaluate personalities and contribution of one potential group members".

EDWIN B.FILIPPO, defined has the term performance appraisal as " A systematic ,periodic and so far as humanly possible, an impartial rating of an employee's excellence in matters pertaining to his present to his present job and his potentialities for a better job “. 
According to JOHN A. SHUBIN defined as "Merit rating is a systematic appraisal of the employee's personality and performance on the job and is designed to determine his contribution and relative worth to the firm".

In the words of L. A. LARKIN, "Performance appraisal is the systematic assessment by merit factors of the behavior and /or ability of workers in their work and a means whereby each worker may be rewarded a percentage in addition to his wage according to his assessed merit value".

\section{Review Of Literature:}

ALFORD AND BEATTY says, "It is the evaluation or appraisal of the relative worth to the company of a man's service on the job".

FLIPPER says, "Performance Appraisal is a systematic, periodic and so far as humanly possible and impartial rating of employee's excellence of matters pertaining to his potentialities for a better job".

Performance appraisal has been defined in many ways. The simplest way to understand the meaning of performance appraisal is as follows:

"A regular and continuous evaluation of the quality, quantity and style of the performance along with the assessment of the factors influencing the performance and behavior of an individual's called performance appraisal".

Cleveland, Murphy, and Williams (1989) argued that there is a relationship between organizational characteristics and the uses of a performance appraisal system. Stonich (1984) also argued that performance measurement in an organization should be in tune with its structure and culture. Since the nature of the enterprises in which each industry is engaged varies, its organizational type, business policy, internal and external environment are also usually different. The purpose of this study is to conduct a direct comparative analysis of performance appraisal system in the service and manufacturing industries.

Apart from organizational control, Ilgen, Barnes-Farrell, and McKellin (1993) concluded, from their extensive review of the literature since the 1980s about performance appraisal, that there are four aspects that need to be considered. In practice performance appraisal systems cover a wide range of these aspects, and seldom have exactly the same nature and functions. In order to integrate findings in the area, Chu (2002) proposed a comprehensive framework including six categories, namely, appraisal purposes, appraises personnel, appraisal criteria, appraisal methods, appraisal timings, and appraisal feedback. This study will adopt this framework to compare performance appraisal systems in the service and manufacturing industries

\section{Theoretical Background \\ OVERVIEW OF THE PERFORMANCE APPRAISAL SYSTEM:}

Performance appraisal is the process of making an assessment of the performance and progress of the employees of an organization. Once an employee has been inducted into the organization and given the necessary training, the next step is to assess his performance periodically. Such assessment would indicate whether he is efficient or not. Performance appraisal is also known as "merit rating" or "efficiency rating".

The following factors are given weight age in evaluating the performance and progress of an employee:

* Knowledge of work

* Extent of co-operation with colleagues and superiors.

* Initiative

* Quality of work.

- Target attainment.

* Aptitude.

* Degree of skill.

* Discipline

* Punctuality

* Honesty

* Ambition

* Crisis management, etc.

\section{Performance appraisal to performance development:}

In fact, performance appraisal, in recent times, emerged as performance analysis and development. Performance analysis and development is a departure from the traditional and controlling approach. It views from the development aspect of the employee. Therefore, the main purpose of performance analysis and development is to analyze the present performance of the employee from multiple viewpoints, observe the gap/developmental needs and develop the employee. 
Performance appraisal is also a technique of HRD. The performance interview and the process of the performance analysis help the subordinate to interact closely with his superior. The interaction helps particularly subordinates learn from his superior the job related and behavior related aspects. This process becomes a training/development /educational process. Thus, performance appraisal is closely related to HRD. In fact, performance appraisal helps employee development.

\section{PURPOSE OF PERFORMANCE APPRAISAL SYSTEM:}

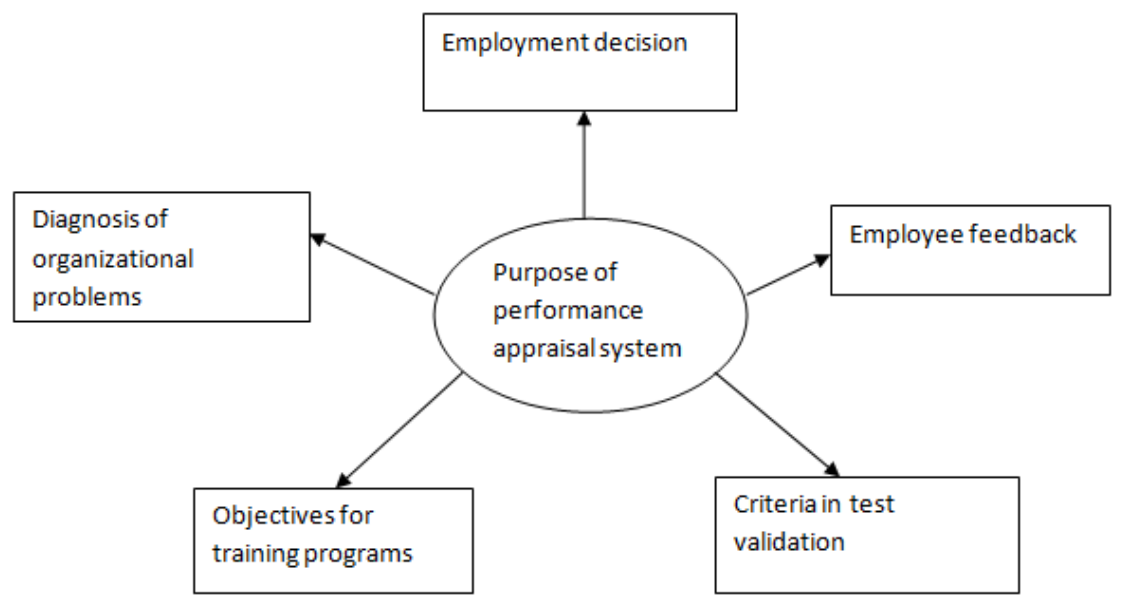

\section{METHODS OF PERFORMANCE APPRAISAL:}

With the evolution and development of the appraisal system, a number of methods or techniques of performance appraisal have been developed. The importance's among them are presented.

Methods of performance appraisal

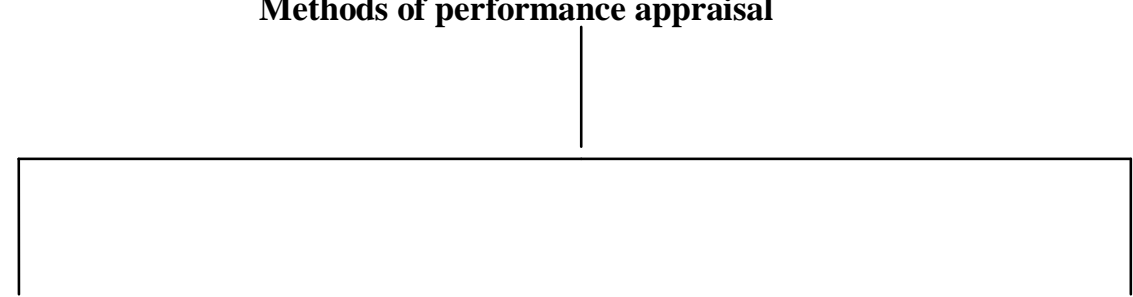

Traditional Methods

Modern Methods

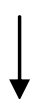

a) Graphic Rating Scales

b) Ranking Method

c) Paired Comparison Method

d) Forced distribution Method

e) Checklist Method

i) Simple checklist

ii) Weighted Checklist

iii) Critical Incident Method

f) Essay or free form Appraisal

g) Group Appraisal

h) Confidential Reports a) Behaviorally Anchored Rating Scales

b) Assessment Center

c) Human Resources Accounting

d) Management by Objectives

e) Behavior Observation Scales

f) Psychological Appraisal

g) Results Method

h) Productivity Measures

I) Balance Score Card

\section{Traditional Methods:}

Graphic Rating Scales:

Graphic rating scales compare individual performance to an absolute standard. In this method, judgments about performance are recorded on a scale. This is the oldest and widely used technique .This method is also known as linear rating scale or simple rating scale. The appraisers are supplied with printed forms, one for each employee. These forms contain a number of objectives, behavior and trait based qualities and characters to be rated like quality and volume of work, job knowledge, dependability, initiative, attitude etc. Rating scales are of two types: 
1. Continuous rating scale

2. Discontinuous Scale

In Continuous order like 0, 1,2,3,4 and 5 and in discontinuous scale, the appraiser assigns the points to each degree .performance regarding each character is known by the points given by the rater. The points given by the rater to each character are added up to find out the overall performance. Employees are ranked on the basis of total points assigned to each one of them.

\section{Ranking Method:}

Under this method, the employees are ranked from best to worst on some characteristics. The rater first finds the employee with the highest performance and the employees with the lowest performance in that particular job category and rates the former as the best and latter as the poorest. Then the rater selects the next highest and next lowest and so on, until he rates all the employees in that group.

\section{Paired Comparison Method:}

This method is relatively simple .under this method, the appraiser ranks the employees with all other employees in the group, one at time.

Paired comparison does not force distribution of employees in each department. For instance, if a department has two outstanding employees and six average employees and paired comparison is correctly utilized, then those employees will get a much higher percentage of positive comparison than the other six. Paired comparison method could be employed fairly easily where the number of employees is less.

\section{Forced Distribution Method:}

The rater may be his employees at the higher or at the lower end scale under the earlier methods. Forced distribution method is developed to prevent the raters from rating too high or too low. Under this method, the rater after assigning the points to the performance of each employee has to distribute his ratings in a pattern to conform to normal frequency distribution.

Thus, similar to the ranking technique, forced distribution require the raters to spread their employees evaluations in a prescribed distribution. This method eliminates central tendency and leniency biases. However, in this method, employees are placed in certain ranked within the categories.

\section{CHECKLIST METHODS:}

The checklist is a simple rating technique in which the supervisor is given a list of statement or words and asked to check statement representing the characteristics and performance of each employee. There are three types of checklist methods.

\section{I) Simple checklist method:}

The checklist consists of large number of statement concerning employee behavior. The rater checks to indicate if the behavior of an employee is positive or negative to each statement may appear to be virtually identical in describing the employee. The words or statement may have different meaning to different raters.

\section{II) Weighted Checklist:}

The weighted checklist method involves weighted different items in the Checklist, having a series of statement about an individual, to indicate that some are important than others. The rater is expected to look into the questions relating to the employee's behavior, the attached rating scale (or simply positive/ negative statement where such a scale is not provided) and tick those traits that closely describe the employee behavior.

\section{III) Forced Choice Method:}

This method was developed at the close of World War II. Under this method, a large number of statements in groups are prepared. Each group consists of four descriptive statements concerning employee behavior. Two statements are most descriptive and two are least descriptive of each tetrad. Sometimes, there may be five statement in each group out of which one would be neutral. The actual weight age of the statement are kept secret.

\section{Critical Incident Method:}

Employees are rated discontinuously, i.e., once in a year or six months under the earlier methods. The performance rated may not reflect real and overall performance as the rater would be serious about appraisal. Hence, a continuous appraisal methodize, the critical incident method has been developed under this method, the supervisor continuous records the critical incidents of the employee performance or behavior relating to all characteristics in a specially designed. The supervisor rates the performance of his subordinates on 
his subordinates on the basis of notes taken by him. Since the critical incident method does not necessarily have to be separate rating system, it can be fruitfully employed as documentation of the reasons why an employee was rated in a certain way.

\section{Essay or Free Form Appraisal:}

This method requires then manager to write a short essay describing each employee's performance during the rating period. This format emphasizes evaluation of overall performance, based on strengths/weaknesses of employee performance rather than specific job dimensions. By asking supervisors to enumerate specific examples of employee behavior, the essay technique minimizes supervisory bias and the halo effect.

\section{Group Appraisal:}

Under this method, an employee is appraised by a group of appraisers. This group consists of the immediate supervisor of the employee to other supervisors who have close contact with the employee's work, manager or head of the department and consultants. The head of the department or manager may be the chairman of the group and the immediate supervisor may act as the coordinator for the group activities. This group uses any one or multiple techniques discussed earlier.

Confidential Reports: ssessing the employee's performance confidentially is a traditional method of performance appraisal. Under this method, the supervisor appraises the performance of his subordinates based on his observation, judgment and intuitions. The supervisor keeps his judgment and report confidentially. In other words, the superior does not allow the employee to know the report and his performance. The superior keep his judgment and report confidentially. In other words, the superior does not allow the employee to know the report and his performance.

\section{Behaviorally Anchored Rating Scales:}

\section{Modern Methods:}

The Behaviorally Anchored Rating Scales (BARS) method combines elements of the traditional rating scales and critical incident methods. Using BARS, jobs behaviors from critical incidents - effective and ineffective behaviors are described more objectively. The method employs individual who are familiar with a particular job to identify its major components. They then rank and validate specific behavior for each of the respondents.

\section{Assessment Center:}

This method of appraising was first applied in the German Army in1930.Later, business and industrial houses started using this method. This is not a technique of performance appraisal by itself. In fact, it is a system or organization, where assessment of several individual is done by various experts by using various techniques. These techniques include the methods in addition to in basket, role playing, and case studies ,stimulation in sight, transactional analysis etc.,

\section{Human Resource Accounting:}

Human Resource Accounting deals with cost of and contribution of human resource to the organization. Cost of the employee includes cost of manpower planning, recruitment, selection, induction, placement, training, development, wages and benefits. Employee contribution is the money value of employee service which can be measured by labor productivity or value added by human resource.

\section{Management by Objectives:}

Management by Objectives (MBO) is a process whereby the superior and subordinate managers of an organization jointly its common goals, define each individual's ajor areas of responsibility in terms of results expected of him and use these measures of guides for operating the unit and assessing the contribution of its members. Thus, MBO focuses attention on participative set goals that are tangible, verifiable and measurable. The emphasis is on what must be accomplished rather than how it is to be accomplished.

* The subordinate and superior jointly determine goals to be during the appraisal period and what level of performance is necessary for the subordinate to satisfactory achieve specific goals.

* During the appraisal period, the superior and subordinate update and alter goals as necessary due to changes in the business environment.

* Both superior and subordinates jointly discuss whether the subordinate achieved the goals or not. If not, they should identify the reasons for strike/lock-out, market change etc. 


\section{Behaviors Observation Scales (BOS):}

The appraiser, under this method, measures how frequently each of the behavior has been observed .Appraiser plays the role of observer rather than a judge and provides the feedback to the appraise continuously.

i) Maintain objectivity

ii) Differentiate good performers from poor performers

iii) Provides feedback and

iv) Identify training needs better than those chosen by other methods.

\section{Psychological Appraisal:} appraisals consist of:

Psychological appraisals are conducted to assess the employee's potential. Psychological

a) In depth interviews

b) Psychological tests

c) Consultations and discussions with the employees,

d) Discussions with the superior, subordinates and peers, and

e) Reviews of other evaluations.

The Psychological appraisal results are useful for decision making about I) employee placement, II) Career-planning and development, and III) Training and development.

\section{Result Method:}

Organizations of the contemporary periods evaluate employee performance based on accomplishments they achieve rather than behavioral factors/traits. Employee accomplishments include sales turnover, number of units produced, and number of customers served, number of complaints settled and the like. Productivity Measures:

Under the productivity measures of performance appraisal, employees are appraised based on the ratio of output they turned out to the input they used. Examples sales to employee salary and benefits, number of clients served per day etc. These measures are not free from limitations as measurement of all kinds of output as well as all kinds of input would be difficult.

\section{The Balance Scorecard:}

The balanced scorecard was developed by Robert Kaplan and David Norton .It brings the linkages among financial, customer, processes and learning. Learning and people management contribute to the enhancement of internal processes. Internal processes are critical for enhancing customer satisfaction and loyalty. Customer satisfaction leads to customer value creation, which drives financial performance and profitability.

\section{SEVERAL WAYS OF PERFORMANCE APPRAISAL:}

Performance appraisals are useful for the organizations in several ways including:

* Professional development (identifying strengths and weaknesses in performance, implementing strategies for improvement)

* Determining organizational training and development needs.

* Making and validating administrative decisions (e.g., pay, promotion, placement, and termination)

* Identifying systemic factors that are barriers to, or facilitators of, effective performance.

* Some workers can find performance appraisals to be threatening or intimidating. However, with good Design and planning, performance appraisals can be rewarding and constructive for workers and managers / supervisors. When performance appraisals are clearly linked with recognition and

* Rewards, there are also likely to be benefits for workers' motivation, productivity and retention

\section{FIVE STEPS OF APPROACH TO CONDUCTING A PERFORMANCE APPRAISAL:}

The following five-step approach to conducting a systematic performance appraisal is recommended:

1. Identify key performance criteria

2. Develop appraisal measures

3. Collect performance information from different sources

4. Conduct an appraisal interview

5. Evaluate the appraisal process. 


\section{Using performance appraisal to address workforce development challenges:}

Regular performance appraisals provide a useful opportunity to conduct a "check-up" on various workforce development issues that may impact on workers' effectiveness and wellbeing.

Performance appraisals can be used to:

- Recognize, reward and support effective performance

- Develop and reward effective teamwork

- Identify and manage issues likely to impact on retention

- Monitor and support workers' wellbeing.

\section{RESEARCH METHODOLOGY:}

Research Methodology is the process of systematic investigation of any management problem it deals with research design, data collection method, sampling plan, sampling method. 'Research' means a scientific and systematic search for pertinent information on a specific topic. Research is a careful investigation or inquiry especially through search for new facts in any branch of knowledge. Research comprises defining and redefining problems, formulating hypothesis or suggested solution; collecting, organizing and evaluating data, making deductions and reaching conclusions; and at last carefully testing the conclusions to determine whether they fit the formulating hypothesis.

'Methodology' is defined as "the study of methods by which we gain knowledge, it deals with cognitive processes imposed on research to the problem arising from the nature of its subject matter".

\section{RESEARCH DESIGN:}

The study is to measure effectiveness of the training program through performance appraisal system provided by the employees.

Descriptive research is also called statistical research the main goal of this type of research is to describe the data and characteristics about what is being studied. The idea behind this type of research is to study frequencies, averages and other statistical calculations. Although this research is highly accurate, it does not gather the causes behind situation. Descriptive research is mainly done when a research is mainly done when a research wants to gain a better understanding of a topic.

Descriptive research answer the questions who, what, where, when and how.

\section{DATA COLLECTION METHOD: PRIMARY DATA:}

Primary data is known as data collected for the first time through field survey. Such data are collected with specific set objectives. Primary data always reveals the cross section picture of anything studied. This is needed in research to study the effect or impact any policy.

\section{SECONDARY DATA:}

Secondary data refers to the information or facts already collected. Such data are collected with the objectives of understanding the past status of any variable data collected and reported by some source is accessed and used for the objectives of the study. The secondary data were collected from:

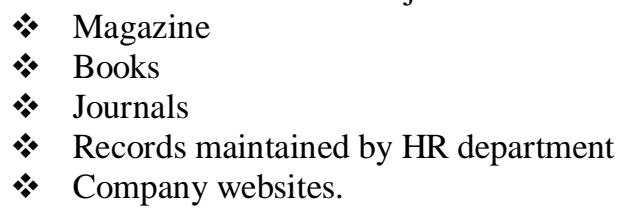

\section{SAMPLING DESIGN:}

\section{STRATIFIED RANDOM SAMPLING:}

A random sample of specified size is drawn from each stratum of a population. Stratified sampling is a method of sampling from a population, when sub-population vary considerably, it is advantageous to sample each sub population (stratum) independently. Stratification is the process of grouping members of the populations into relatively homogenous subgroups before sampling.

\section{SAMPLE SIZE:}

Due to time and resource constraint the sample size is taken as 100 for the survey from the total population (700) employees. 


\section{RESEARCH INSTRUMENT: \\ QUESTIONNAIRE:}

A questionnaire is a research instrument consisting of a series of questions and other prompts for the purpose of gathering information from respondents. Although they are often designed for statistical analysis of the responses.

\section{RESEARCH PLAN:}

Data source

Research approach

Research Instrument

Method of contact

Sample size

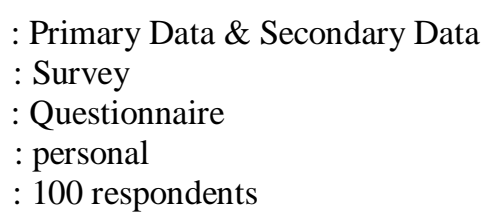

\section{TOOLS FOR ANALYSIS:}

1. Chi-square Analysis

2. Rank correlation method

3. ANOVA

\section{STATISTICAL TOOLS USED:}

The main of the analysis is to determine the relationship between the various factors potential and to determine which factor is significant in enhancing the same .various statistical tools are of:

\section{Chi-Square Analysis:}

Chi square test is non-parametric test used most frequently by marketing research to test hypothesis. The main aim is to determine whether significant difference exist among the groups of data or whether difference due to sampling when a small number of degree of freedom is involved is greater skewed. As the degree of freedom increases, distribution curve became most significant and resembles the nominal curve.

\section{Chi-Square test:}

$$
x^{2}=\sum \quad \frac{(O i j-E i j)^{2}}{\mathrm{Eu}}
$$

Where,

Oij = Observed frequency of the cell in the row and jith column

$\mathrm{Eij}=$ Expected frequency of the cell in the row and jith column.

\section{Chi-Square test:}

$x^{2}$ Test is based on the chi-square distribution and it is parametric test. It is used for comparing a sample variance to a theoretical population variance. In a non parametric test, no assumption about the parameters of the population is made. The non - parametric tests originally were applied in sociological and psychological research.

Conditions to be satisfied for applying chi-square test.

1. Data should have been collected random.

2. Items constituting the sample should be independent

3. The total number of items should at least be 50 .

It has been already stated that chi-square is used for different purpose .These are explained below:

* Chi-square as a goodness of fit.

* Chi-Square as a test of independence

RANK CORRELATION OF CO-EFFICIENT:

$$
\begin{aligned}
& \mathrm{r}=1- \\
& 6 \sum d^{2} \\
& n\left(n^{2}-1\right)
\end{aligned}
$$


* r $=$ coefficient of rank correlation.

Correlation is one of the statistical tools very widely applied as a tool of analysis in every subject. A nonparametric counterpart of the conventional correlation coefficient. A correlation coefficient calculated in this manner is known as the Spearman rank correlation coefficient and is denoted by $\mathrm{r}$.

\section{Advantage of rank correlation:}

1. We do not assume the underlying relationship between $\mathrm{x}$ and $\mathrm{y}$ to be linear and, therefore when data posses a distinct curvilinear relationship, the rank correlation coefficient will likely be more reliable than the conventional measure.

2. The greatest advantage occurs when one is unable to make meaningful numerical measurements but nevertheless can establish rankings.

\section{ANOVA:}

Another test of significance is analysis of variance test (ANOVA). The primary purpose of ANOVA is to test for the differences between multiple means. It can be calculated by comparison of two tools of data with difference in sample. It can be calculated as

* Identify the independent and dependent variables.

* Describe the variation by breaking it into parts the total variation.

* The portion that is within groups and the portion is between groups (or among groups for more than two groups).

* Measures the difference between each goup's mean and the grand mean.

Perform a significance test on the difference $\&$ interpret the results. The above steps can be interpreted as follows.

\section{Source of variation \\ SSC \\ SSR \\ E SS}

\section{- Sum of squares \\ - Sum of squares of rows. - Error sum of squares.}

By taking degree of freedom and taking into consideration the above variation, the variance is calculated and the F-ratio is got from the mentioned variants. ANOVA at last is accepted by comparing the calculated and tabulated value.

ANOVA is accepted when the calculated value is less than the tabulated value and rejected vice versa. ANOVA is efficient for analyzing data using relatively few observation $\mathrm{s}$ and can be used with categorical variables.

\section{DATA ANALYSIS AND INTERPRETATION:}

Analysis and interpretation of various statements gives a skilled and experienced for a better understanding and the performance of the firm.

The term "analysis " means methodical classification of the data requires a number of closely related operations such as establishment of categories to raw data through coding, tabulation and then drawing statistical inferences. Where the term "interpretation" means expanding the meaning and significance of the data so simplified.

$\mathrm{f}$ the respondents feel excellent that improvement in work area.34\% of the respondents feel very good were improvement required quality and housekeeping area. $24 \%$ of the respondents were good, $9 \%$ of the respondents feel improvement required, $5 \%$ of respondents feel unsatisfactory. Hence the maximum numbers of employees are suggestion and implementation to improvement in work area.

\section{STATISTICAL ANALYSIS HYPOTHESIS TEST -1}

\section{CHI-SQUARE}

To find out any significant difference between the appraisals systems helps to identify the strength and weakness of employees and rating helps for management to provide employee counseling.

\section{Hypothesis}


Null Hypothesis (H0) : There is no significant relationship between the appraisal system identifying the strength and weakness of employees and also management provide employee counseling.

Alternate Hypothesis (H1): There is a significant relationship between the appraisal system identifying the strength and weakness of employees and also management provide employee counseling.

TABLE SHOWING THE APPRAISAL SYSTEM IDENTIFY THE STRENGTH AND WEAKNESS OF EMPLOYEES AND MANAGEMENT PROVIDE EMPLOYEE COUNSELING

\begin{tabular}{|c|c|c|c|c|c|c|c|}
\hline \multicolumn{2}{|r|}{ OPTION } & \multicolumn{5}{|c|}{$\begin{array}{l}\text { STRENGTH AND WEAKNESS OF } \\
\text { EMPLOYEES }\end{array}$} & \multirow[t]{2}{*}{$\begin{array}{l}\text { TOT } \\
\text { AL }\end{array}$} \\
\hline \multirow{6}{*}{ 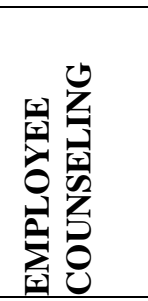 } & OPINION & $\begin{array}{l}\text { VERY } \\
\text { GOOD }\end{array}$ & GOOD & NEUTRAL & $\begin{array}{l}\text { BA } \\
\text { D }\end{array}$ & $\begin{array}{l}\text { VERY } \\
\text { BAD }\end{array}$ & \\
\hline & HIGHLYSATISFIED & 10 & - & - & - & 4 & 14 \\
\hline & SATISFIED & - & 13 & - & 23 & - & 36 \\
\hline & NEUTRAL & - & - & 25 & 3 & - & 28 \\
\hline & DISSATISFIED & 4 & - & 14 & - & - & 18 \\
\hline & HIGHLYDISSATISFIED & 1 & - & - & - & 3 & 4 \\
\hline TOTAL & & 15 & 13 & 39 & 26 & 7 & 100 \\
\hline
\end{tabular}

$\mathbf{E}=\mathbf{R} * \mathbf{C} / \mathbf{N}$

Where $\mathrm{R}=$ sum of row total

$\mathrm{C}=$ sum of column total

$\mathrm{N}=$ sample size

Calculated value

\begin{tabular}{|c|c|c|c|}
\hline $\begin{array}{l}\text { Observed } \\
\text { frequencies(O) }\end{array}$ & Expected Frequencies (E) & $(\boldsymbol{O}-\boldsymbol{E})^{\mathbf{2}}$ & $(\boldsymbol{O}-\boldsymbol{E})^{\mathbf{2}} / \boldsymbol{E}$ \\
\hline 10 & 2.1 & 62.41 & 29.72 \\
\hline 4 & 0.98 & 9.1204 & 9.31 \\
\hline 13 & 4.68 & 69.22 & 14.79 \\
\hline 23 & 9.36 & 186.05 & 19.87 \\
\hline 25 & 10.92 & 198.24 & 18.15 \\
\hline 3 & 7.28 & 18.31 & 2.515 \\
\hline 4 & 2.7 & 1.69 & 0.625 \\
\hline 14 & 7.02 & 48.72 & 6.940 \\
\hline 1 & 0.6 & 0.16 & 0.267 \\
\hline 3 & 0.28 & 7.398 & 26.42 \\
\hline \multicolumn{2}{|r|}{ CALCULATED VALUE } & & 128.607 \\
\hline
\end{tabular}

Calculated value of chi-square $\left(\varphi^{2}\right)=128.607$

Table value of chi-square

Degree of freedom $=($ row -1$) *($ column -1$)$

$$
\begin{aligned}
& =(5-1) *(5-1) \\
& =4 * 4 \\
& =16
\end{aligned}
$$

Critical value: the table value of $\varphi^{2}$ at $5 \%$ and for 16 degree of freedom is $\varphi^{2}(0.05,16)=26.296$

\section{INTERPRETATION:}

Since the calculated value of e $\left(\varphi^{2}\right)=128.607$ is $>\varphi^{2}(0.05,16)=26.296$, so the null hypothesis (H0) is rejected and the alternate hypothesis (H1) is accepted.

\section{RESULT:}

From the above test we find it that there is a relationship between the appraisal system identify strength and weakness of employees and rating helps to provide employee counseling.

HYPOTHESIS TEST -2

Calculation of spearman's rank correlation co-efficient.

The observed value of opinion regarding the promotion is purely based on performance appraisal and the rating helps to fix increments. 
“A Study On Performance Appraisal System At Wipro Infrastructure Engineering Pvt Ltd”

\begin{tabular}{|l|l|l|}
\hline opinion & No. of Respondents & $\operatorname{Rank}(\mathrm{X})$ \\
\hline Highly satisfied & 37 & 1 \\
\hline Satisfied & 16 & 3 \\
\hline Neutral & 24 & 2 \\
\hline Dissatisfied & 13 & 4 \\
\hline Highly dissatisfied & 10 & 5 \\
\hline
\end{tabular}

The observed value regarding the organization provides additional benefits for your work development.

\begin{tabular}{|c|c|c|}
\hline Opinion & No. of Respondents & Rank (Y) \\
\hline Strongly agree & $\mathbf{1 8}$ & 3 \\
\hline Agree & 9 & 4 \\
\hline Neutral & 42 & 1 \\
\hline Disagree & 25 & 2 \\
\hline Strongly disagree & 6 & 5 \\
\hline
\end{tabular}

\section{Calculation of correlation:}

\begin{tabular}{|l|l|l|l|}
\hline Rank (x) & Rank $(\mathrm{y})$ & $\mathrm{D}=\mathrm{x}-\mathrm{y}$ & \multicolumn{1}{c|}{$\boldsymbol{D}^{\mathbf{2}}$} \\
\hline 1 & 3 & -2 & 4 \\
\hline 3 & 4 & -1 & 1 \\
\hline 2 & 1 & 1 & 1 \\
\hline 4 & 2 & 2 & 4 \\
\hline 5 & 5 & 0 & 0 \\
\hline & & & 10 \\
\hline
\end{tabular}

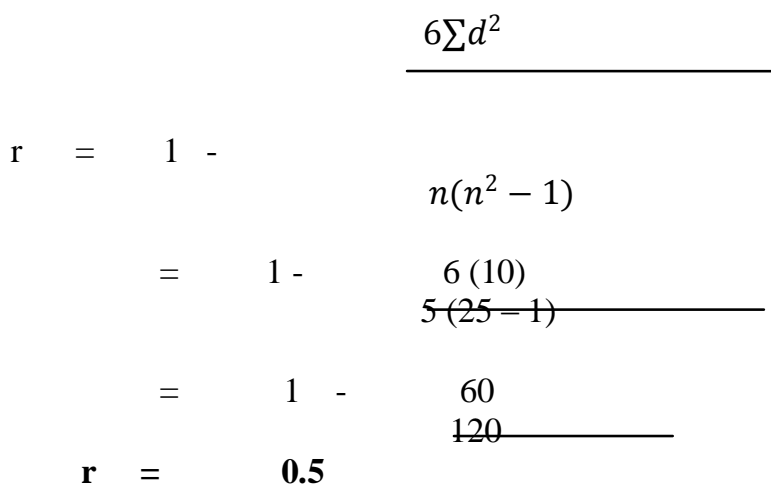

\section{RESULT:}

Also $\mathrm{r}=0.5$ indicates a high positive correlation between the promotion is purely based on appraisal and the rating helps to fix increment and also the organization provide additional benefit for your work development.

\section{HYPOTHESIS TEST -3}

\section{ANOVA}

To find out any significant relationship between the effectiveness of performance appraisal \& development programme and satisfaction of present appraisal system done by organization.

\section{Hypothesis}

Null Hypothesis (H0) - There is no significant relationship between the effectiveness of appraisal \& development programme and satisfaction of present appraisal done by organization.

Alternate Hypothesis (H1) - There is a significant relationship between the effectiveness of appraisal \& development programme and satisfaction of present appraisal done by organization. 
TABLE SHOWING THE EFFECTIVENESS OF APPRAISAL \& DEVELOPMENT PROGRAMME AND SATISFACTION OF PRESENT APPRAISAL DONE BY ORGANIZATION.

\begin{tabular}{|c|c|c|c|c|c|c|c|}
\hline \multirow[b]{2}{*}{ S.NO } & \multirow[b]{2}{*}{ EFFECTIVENESS } & \multicolumn{6}{|c|}{ SATISFACTION OF APPRAISAL DONE BY ORGANIZATION } \\
\hline & & $\begin{array}{l}\text { Strongly } \\
\text { agree }\end{array}$ & Agree & Neutral & Disagree & $\begin{array}{l}\text { Strongly } \\
\text { disagree }\end{array}$ & Total \\
\hline 1 & Highly effective & - & - & - & 10 & 15 & 25 \\
\hline 2 & Effective & 10 & 20 & 15 & - & 5 & 50 \\
\hline 3 & Neutral & 5 & 5 & - & - & - & 10 \\
\hline 4 & Ineffective & - & 5 & - & - & - & 5 \\
\hline 5 & Highly Ineffective & 5 & - & - & - & 5 & 10 \\
\hline & Total & 20 & 30 & 15 & 10 & 25 & 100 \\
\hline
\end{tabular}

Calculation

Correction Factor $($ C.F $)=T^{2} / \mathrm{N}$

$$
\begin{aligned}
& =100^{2} / 25 \\
& =10,000 / 25 \\
& =400
\end{aligned}
$$

Sum of Square of Total Variance: (SST)

$$
\begin{aligned}
& =\text { sum of squares of all items }- \text { C.F } \\
& =\left[10^{2}+1^{2}+10^{2}+20^{2}+15^{2}+5^{2}+5^{2}+5^{2}+5^{2}+5^{2}+5^{2}\right]-400 \\
& =1200-400 \\
& =800
\end{aligned}
$$

Sum of Squares between rows (SSR)

\begin{tabular}{|c|c|c|c|c|}
\hline $\begin{array}{l}\text { SOURCE OF } \\
\text { VARIANCE }\end{array}$ & $\begin{array}{l}\text { SUM OF } \\
\text { SQUARES }\end{array}$ & $\begin{array}{l}\text { DEGREE OF } \\
\text { FREEDOM }\end{array}$ & VARIANCE & $\mathbf{F}$ \\
\hline Between rows & 270 & $5-1=4$ & $270 / 4=67.5$ & $\begin{array}{l}\text { 67.5/28.4375 = } \\
2.3736\end{array}$ \\
\hline Between columns & 75 & $5-1=4$ & $75 / 4=18.75$ & $\begin{array}{l}18.75 / 28.4375 \\
=0.6593\end{array}$ \\
\hline Residual & 455 & $(4) *(4)=16$ & $455 / 16=28.4375$ & \\
\hline
\end{tabular}

$$
\begin{aligned}
& =\left[\left(25^{2} / 5\right)+\left(50^{2} / 5\right)+\left(10^{2} / 5\right)+\left(5^{2} / 5\right)+\left(10^{2} / 5\right)\right]-400 \\
& =670-400 \\
& =270
\end{aligned}
$$

Sum of Squares between the columns (SSC)

$$
\begin{aligned}
& =\left[\left(20^{2} / 5\right)+\left(30^{2} / 5\right)+\left(15^{2} / 5\right)+\left(10^{2} / 5\right)+\left(25^{2} / 5\right)\right] \\
& =475-400 \\
& =75
\end{aligned}
$$

Error Sum of Squares $=$ SST $-($ SSR + SSC $)$

$$
\begin{aligned}
& =800-(270+75) \\
& =455
\end{aligned}
$$

ANOVA TABLE

Calculated Value

F1 $=2.3736$

$\mathrm{F} 2=0.6593$

\section{Table Value}

Critical value: The table value of ANOVA at $5 \%$ and the degree of freedom is $(4,16)=3.01$ 
RESULT

The table value of $\mathrm{F} 1$ at 0.05 level of significance is 3.01. Calculated value is 2.3736. Hence calculated value is lesser than table value, so $\mathrm{H} 0$ is accepted. Since there is no

significant relationship between the effectiveness of appraisal \& development programme and satisfaction of present appraisal done by organization.

The table value of F2 at 0.05 level of significance is 3.01. Calculated value is 0.6593 . Hence calculated value is lesser than table value, so $\mathrm{H} 0$ is accepted. Since there is no significant relationship between the effectiveness of appraisal \& development programme and satisfaction of present appraisal done by organization.

\section{FINDINGS OF THE STUDY:}

$>50 \%$ of the respondents to the age group of 20-30years.

$>60 \%$ of the respondents have the qualification ITI/Diploma.

$>75 \%$ of the respondents have the experience for below 2 years.

$>45 \%$ of the respondents belong to the salary range below 10,000 .

$>31 \%$ of the respondents feel satisfied in the present performance appraisal system.

$>63 \%$ of the respondents are said to that additional benefits are not achieved by them.

$>65 \%$ of respondents feel annually the performance appraisal is conducted.

$>49 \%$ of respondent's opinion about the effectiveness of performance appraisal and its development programme.

$>43 \%$ of the respondents strongly agree with their opinion that appraisal is very much needed in organization.

$>60 \%$ of the respondents feel that they are partly aware of appraisal techniques and parameter.

7 $40 \%$ respondents strongly agree in safety adopted in organization is very helpful for their work activities.

$>30 \%$ of the respondents say that the performance appraisal rating can be done through departmental managers.

$>37 \%$ of the respondents highly satisfied with the co-operation and team work.

$>42 \%$ of the respondents say that they need team work from superior in the organization.

$>35 \%$ of the respondents feel that the incentives provides a maximum benefits and it provide greater job satisfaction.

$>42 \%$ of the respondents strongly agree with the organization provide additional benefits for employee work development.

$>39 \%$ of the respondents feel neutral that appraisal helps to identify the strength and weakness of employees.

$>37 \%$ of the respondents agree with that the promotion is purely based on performance appraisal.

$>36 \%$ of the respondents satisfied with the performance rating helps to provide employee counseling.

$>74 \%$ of the respondents say that ranking method is being followed in organization.

$>88 \%$ of the respondents feel that there is a communication between top management and business goals to staff.

$>37 \%$ of the respondents are strongly agreed with that there comments and suggestion are considered during appraisal.

$>31 \%$ of the respondents are strongly agree with the desired target of the organization is achieved through performance appraisal.

$>34 \%$ of the respondents feel very good were improvement required in quality and housekeeping area.

$>$ In chi-square test based on there is a relationship between the appraisal systems identifying strength and weakness of employees and rating helps to provide employee counseling.

$>$ In rank correlation coefficient based on the high positive correlation between the promotion is purely based on appraisal and the rating helps to fix increment and also the organization provide additional benefit for your work development.

> In ANOVA based on the effectiveness of appraisal system and its satisfaction of present performance appraisal system done by the organization.

\section{Suggestions}

While framing the parameters in the ranking method the performance appraisal technique and group discussion can be made among and with various authorities. Secondly, the techniques used for performance appraisal are very traditional which is to be modernized in future for good prospect of the employees. Increase the awareness level of employees during the performance appraisal period. It will be better if the management provides incentives to employees so it will boost in their work and productivity and also extend the probation period up to 2 years. Separate rating committee to be fixed during the appraisal period. So that there is no rating biases and personal prejudice will occur. The performance rating is very helpful for management to provide 
employee counseling during the appraisal. Performance appraisal is purely based on appraisal system and the rating helps to fix increment for workers make them retained in the organization. Supervisors should maintain cordial relationship with workers and offers recognitions of the employee's efforts and provide guidance to workers. During the appraisal period provide a good communication between top management and business goals to staff so that the desired target of the organization can be achieved through performance appraisal. Employee comments and suggestion to be considered during the appraisal. It will be better if the management provide performance and potential appraisal rewards regularly.

\section{Conclusion:}

Human resources are the vital source of every organization. Every employee in an organization increases the productivity and goodwill of every company. An employee, being an individual is treated as assets in the organization. So the organization should mainly emphasis performance appraisal techniques and its development programme. Both the appraiser and appraise should realize the principle and use the tool of appraisal system in a constructive way for the prosperity of the organization.

The performance appraisal technique prevailing in the organization is fair. Employees are satisfied with the present performance appraisal system that is a traditional one. As many new appraisal techniques are emerged, the organization can implement modern technique which would be more effective. The welfare measure of organization is at par with the company policies and has brought a great sense of involvement in work among the employees of the organization. If the suggested measures are taken into consideration it will help to increase the effectiveness of performance appraisal system.

\section{McGraw Hill, 2003.}

\section{Reference:}

[1]. Radha, "Human Resource Management “, Himalaya Publication.

[2]. Arora P.N and Arora .S "Statistics for Management", "First Edition Chard's \& company ltd". New Delhi 2008

[3]. C.R .Kothari, "Research Methodology", New Age International Publishers. Second revised edition; 2004

[4]. R.Senapathi, "Research methodology", Lakshmi publication; First edition. 